\title{
Association between Serum Calcidiol Levels and Cognitive Function in Geriatric Patients
}

\author{
Sandy Anandhita1), Fatichati Budiningsih2), Arief Nurrudhin²) \\ 1)Masters Program in Family Medicine, Universitas Sebelas Maret \\ 2)Department of Internal Medicine, Faculty of Medicine, Universitas Sebelas Maret/ \\ Dr. Moewardi Hospital, Surakarta
}

Background: The role of vitamin D toward cognitive function is as neuroprotective in which vitamin D will increase neurotrophic factor production which contributes to supporting neuron life sustainability, development, and function. The study aims to analyze the association between calcidiol serum level and cognitive functions of geriatric patients.

Subjects and Method: A cross-sectional study was conducted at Geriatric Polyclinic of dr. Moewardi Hospital, Surakarta. A sample of 30 geriatric patients was selected randomly. The dependent variable was cognitive functions (MMSE score). The Independent variable was calcidiol serum level. The data were analyzed by Spearman test.

Results: There was no difference of calcidiol serum level with MMSE score $(\mathrm{OR}=1 ; \mathrm{p}=0.478)$.

Conclusion: There was no difference in calcidiol serum level with MMSE score.

Keywords: cognitive functions, calcidiol

\section{Correspondence:}

Sandy Anandhita. Masters Program in Family Medicine, Universitas Sebelas Maret. Jl. Ir. Sutami 36A, Surakarta, Central Java. Email: anandhitasandy3@gmail.com. Mobile:082227940410

Cite this as:

Anandhita S, Budiningsih F, Nurrudhin A (2020). Association between Serum Calcidiol Levels and Cognitive Function in Geriatric Patients. Indones J Med. 05(03): 185-190. https://doi.org/10.26911/theijmed.2020.05.03.02.

cc (i) (2) Indonesian Journal of Medicine is licensed under a Creative Commons

Attribution-Non Commercial-Share Alike 4.o International License.

\section{BACKGROUND}

The prevalence of elderly over 60 years of age is increasing faster than the population of other age groups because of the increase in life expectancy rate and the decline in birth rate. Global demography data indicates the population of the elderly over 60 years of age triples within 50 years. From 600 million in 2000 to become more than 2 billion in 2050. The elderly population in Indonesia is the top five in the world. 18.1 million in 2010 and it will double into 36 million in 2025. Indonesia life expectancy rate reached 67.8 years in 2000-2005 and is turning into 73.6 in 20202025. The proportion of the elderly increased to $6 \%$ in $1950-1990$ and $8 \%$ today. The proportion is estimated will increase to $13 \%$ in
2025 and $25 \%$ in 2050. In 2050 a quarter of the Indonesian population will be elderly, compares to one-twelfth of the Indonesian population today (Setiati et al., 2011).

Population-based study toward the elderly over 65 years of age in Europe and the USA indicates that vitamin D deficiency is commonly found although the level may differ in each country. For example the data from Health Survey for England (HSE) 2005 reveals that the majority of elderly over 65 years of age $(n=2070)$ have calcidiol serum level < $50 \mathrm{nmol} / \mathrm{L}$ (male: $49 \%$, female: $58 \%$ ), and $<25 \mathrm{nmol} / \mathrm{L}$ (male: $8 \%$, female: $14 \%$ ). In the Netherlands, the result of calcidiol serum level examination among respondents who participated in Longitudinal Aging Study 
Amsterdam (LASA), also indicates the low level $<50 \mathrm{nmol} / \mathrm{L}$ in $48,4 \%$ and $<25 \mathrm{nmol} / \mathrm{L}$ in $11,5 \%$ respondents. In the USA, the data obtained from National Health and Nutrition Examination Survey (NHANES) 2000 - 2004 indicates that one forth male (50-69 years: 27\%; $\geq 70$ years: $27 \%$ ) and one-third female (50-69 years: $36 \%$; $\geq 70$ years: $34 \%$ ).

Cognitive function impairment among the elderly is one of the serious health problems in developed as well as developing countries, such as Indonesia. It is caused by the more surfacing degenerative diseases and the increasing life expectancy age. Prevalence study indicates that in the USA, among the population of over 65 years of age, the percentage of people with Alzheimer (the major cause of dementia), doubles with every 5 years of increase in age. Without adequate prevention and medication, the number of patients in the country will be increasing from 4.5 million in 2000 to 13.2 million in 2050. The cost spent on patients treatment is also fantastic, around US\$ 83.9 billion to US $\$ 100$ billion per year (data in the USA year 1996). The cost includes medical cost, long term treatment cost, home treatment cost, and lost productivity cost (Setiati et al., 2011).

A meta-analysis study conducted in 2017 indicates a hypothesis that calcidiol level $\leq 25 \mathrm{nmol} / \mathrm{L}$ increases dementia risk, especially among adults and patients over 65 years of age (Sommer et al., 2017). Hypovitaminosis D is commonly seen among adults and patients over 65 years of age. They show signs of dementia and cognitive impairment (Annweiler et al., 2016).

Several biological mechanisms can elaborate the association between vitamin $\mathrm{D}$ deficiency and the incidence of cognitive function impairment among elderly patients. Vitamin D is neuroprotective since it affects neurogenesis, calcium homeostasis, neurotrophic factors expression, detoxification, amyloid-beta clearance. It is discovered that VDR is found in many organs, including the brain. Subsequently, it is discovered also that VDR and enzyme responsible for active vitamin development in the human brain, $1 \alpha-$ hydroxylase, are widespread in neuron and glial cells inside the brain hemisphere that functions for cognitive. Furthermore, the newest evidence indicates that variation of VDR gen such as Bsml, polymorphism Taql, can affect the possibility of cognitive function decline in the elderly. Vitamin D also stimulates phagocytosis and amyloid-beta clearance (a marker of pathology lesion in Alzheimer's disease) by macrophages and protects the macrophages from apoptosis in Alzheimer patients.

The study aims to analyze the association between Vitamin D serum (calcidiol) level and cognitive functions of geriatric patients. Vitamin D in the study was in the form of 25-(OH)-D or calcidiol. Calcidiol serum level is an indicator of individual Vitamin D status.

\section{SUBJECTS AND METHOD}

\section{Study Design}

A cross-sectional study was conducted in Internal Medicine of Faculty of Medicine, Universitas Sebelas Maret, Surakarta/ Dr. Moewardi Hospital, Surakarta, Central Java, from July to November 2019.

\section{Population dan Sample}

A total of 30 geriatric patients who come for regular check-ups each month to Geriatric polyclinic was selected randomly.

\section{Study Variables}

The dependent variable was cognitive functions. The independent variable was calcidiol serum level.

\section{Operational Definition of Variables} Cognitive functions were a conscious mental activity such as thinking, remembering, and language proficiency. The MiniMental State Examination (MMSE) or Fol- 
stein test is a 30-point questionnaire that is used extensively in clinical and research settings to measure cognitive impairment. The measuring scale used was continuous.

Calcidiol serum was defined as calcidiol is a prehormone that is produced in the liver by hydroxylation of vitamin D3 (cholecalciferol) by the enzyme cholecalciferol 25-hydroxylase. This metabolite can be used to determine a vitamin D status. Calcidiol serum level was measured by a laboratory test. The measurement scale was continous.

\section{Study Instruments}

A blood sample is put into a coded centrifuge tube and left frozen. The frozen blood sample was then rotated for 5-10 minutes at a speed of $4000 \mathrm{rpm}$. Blood processing for its plasma, the storage at a temperature of $-200 C$, and its investigation were conducted in a collaboration with Prodia Clinical Laboratory.

\section{Data Analysis}

Correlation of Vitamin D level and cognitive impairment was analyzed by Spearman test.

\section{RESULTS}

\section{A.Sample Characteristics}

Table 1 showed sample characteristics. Table 2 showed percentage of calcidiol serum level and MMSE score. The majority of the study subjects were at age 65 years $(80 \%)$, had education Junior High School (33.3\%), overweight (60\%), suffered from calcidiol insufficiency (83.3\%), and included in a group with probable MCI/VCI (56.67\%).

Table 1. Sample Characteristics

\begin{tabular}{l|lcc}
\hline Characteristics & Quantity (n) & Percentage \\
\hline Age & 46-55 years & 1 & $3.3 \%$ \\
& 56-65 years & 5 & $16.7 \%$ \\
Education & $\geq 65$ years & 24 & $80 \%$ \\
& Elementary School & 5 & $16.7 \%$ \\
& Junior High School & 10 & $33.3 \%$ \\
\multirow{5}{*}{ Body Mass Index } & High School & 8 & $26.7 \%$ \\
& Bachelor's Degree & 7 & $23.3 \%$ \\
& Underweight & 1 & $3.3 \%$ \\
& Normal & 9 & $30 \%$ \\
& Overweight & 18 & $60 \%$ \\
& Obese & 2 & $6.7 \%$ \\
\hline
\end{tabular}

Table 2. Percentage of calcidiol serum level and MMSE score

\begin{tabular}{clcc}
\hline Variables & \multicolumn{1}{c}{ Categories } & n & \% \\
\hline Calcidiol serum & Deficiency<10 ng/mL & 5 & 16.7 \\
level & Insufficiency 10-29.9 ng/mL & 25 & 83.3 \\
& Normal 30-100 ng/mL & 0 & O \\
MMSE Score & Probable Dementia, score $<24$ & 6 & 20 \\
& Probable MCI/VCI, score 24-28 & 17 & 56.67 \\
& Normal, score $\geq 28$ & 7 & 23.33 \\
\hline
\end{tabular}

\section{B. The result of bivariate analysis}

Table 3 showed spearman correlation test on vitamin D level and cognitive impairment.
Table 3 reported that there was no difference of calcidiol serum level with MMSE score $(\mathrm{OR}=1 ; \mathrm{p}=0.478)$. 
Table 3. Spearman Correlation Test on Vitamin D Level and Cognitive Impairment

\begin{tabular}{|c|c|c|c|c|c|c|}
\hline \multirow{3}{*}{ Calcidiol Serum Level } & \multicolumn{4}{|c|}{$\begin{array}{c}\text { Cognitive Function } \\
\end{array}$} & \multirow{3}{*}{ OR } & \multirow{3}{*}{$\mathbf{p}$} \\
\hline & \multicolumn{2}{|c|}{ MCI/VCI $<24$} & \multicolumn{2}{|c|}{ MCI/VCI $\geq 24$} & & \\
\hline & $\mathbf{n}$ & $\%$ & $\mathbf{n}$ & $\%$ & & \\
\hline Deficiency $<10 \mathrm{ng} / \mathrm{mL}$ & 1 & 20 & 4 & 80 & 1 & 0.478 \\
\hline Insufficiency $10-29.9 \mathrm{ng} / \mathrm{mL}$ & 5 & 20 & 20 & 80 & & \\
\hline
\end{tabular}

\section{DISCUSSION}

The study result indicated that there was no difference between calcidiol serum level and cognitive function. The study result is not in line with several previous studies that concluded there was an increase in the risk of cognitive function impairment among geriatric patients with low serum calcidiol serum level. A meta-analysis study in 2017 revealed a hypothesis that calcidiol concentration $\leq 25$ $\mathrm{nmol} / \mathrm{L}$ increased the risk of dementia especially among adults and patients over 65 years of age (Sommer et al., 2017). Hypovitaminosis D was commonly observed among adults and patients over 65 years of age, where they showed dementia and cognitive impairment signs (Annweiler et al., 2016).

Based on the literature, vitamin D is an important micronutrient for bone growth and calcium homeostasis regulation. Vitamin D does not only play a vital role in bone growth but also holds other important biological roles in one's body functions and development. Recently vitamin $\mathrm{D}$ is getting more recognized as neurosteroid needed by various actions in the brain. Calcidiol circulation crosses brain barriers and enters glial cells and neuron to be modified into calcitriol which is an active form of Vitamin D (Holick et al., 2011).

Annweiler et al. (2016) conducted a study which conveyed neurosteroid action of Vitamin D in calcium homeostatic regulation, $\beta$-amyloid deposition, antioxidant characteristic, and anti-inflammation characteristic. The study discussed the neuroprotection effect of Vitamin D toward the neurodegene- rative process which is related to Alzheimer's disease and cognitive.

The optimal level of calcidiol in blood circulation was needed to maintain neurologic development and protect the adult brain (Sommer et al., 2017).

Balanced food intake is an important lifestyle factor in maintaining cognitive function during the aging period. The newest study also indicated that Vitamin D helped to maintain the cognitive functions of older adults (Anjum et al., 2018).

In the study there was no significant difference between calcidiol serum level in the group with cognitive function impairment and the group without cognitive function impairment. It is because there are other factors, in addition to calcidiol serum level, that can affect cognitive functions decline.

The following are other factors that can affect cognitive function in addition to calcidiol serum level, namely diabetes, obesity, hypertension, hyperlipidemia, smoking history, physical activity, food intake (diet), alcohol, social activity, cognitive practice, education, head trauma, depression, and sleeping disorder (Baumgart et al., 2015).

Based on several current meta-analyses and systematic reviews toward studies of more than 12, it indicates that diabetes is related to cognitive function decline. Based on the meta-analysis and systematic reviews it is revealed that diabetes patients are more likely to suffer from dementia in the future (Baumgart, et al, 2015). Based on current meta-analysis it is assumed that individuals with mild cognitive impairment who suffer from diabetes will progress more rapidly into 
dementia than those who do not suffer from diabetes (Cooper et al., 2015).

Based on several meta-analyses and systematic reviews, the obesity experienced since middle-aged is related to the risk of dementia. However, it may change with age. It is revealed that obesity emerged during older age is related to the decreased risk of dementia (Baumgart et al., 2015). However, a retrospective cohort study indicates that individuals who experienced overweight during middle-aged have a lower risk than underweight individuals (Qizilbash et al., 2015).

Based on a meta-analysis of clinical tests, prospective cohort, observational study, longitudinal study, and cross-sectional study it indicates that there is a significant association between hypertension and cognitive function decline (Baumgart et al, 2015). A systematic review also points out that hypertension therapy can lower down the risk of cognitive decline (Rouch et al., 2015).

Several systematic reviews from prospective study discovers the uncertain result related to the association between high blood cholesterol and dementia (Baumgart et al., 2015).

Based on the result of meta-analysis and systematic review of prospective and longitudinal studies, current smoking history is closely related to cognitive function decline. Based on meta-analysis and systematic review of prospective and longitudinal studies, moderate physical activity is related to the decreased risk of cognitive function decline (Baumgart et al., 2015).

Diet is related to cognitive function. Mediterranean diet (a diet that is loaded with fiber, fruits, vegetables, fish, nuts, and olive oil) and Dietary Approaches to Stop Hypertension (DASH) diet are related to the decreased risk of cognitive functions (Baumgart et al., 2015).

A meta-analysis of prospective and case-control studies indicates that small and moderate amount of alcohol consumption may decrease the risk of cognitive decline. However, excessive alcohol consumption is not suggested for geriatric patients since it is related to the risk of falling (Baumgart et al., 2015).

A Cochrane review indicates that cognitive practice intervention is related to the decreased risk of cognitive function decline. Social activities such as charity programs, going to worship places, visiting favorite clubs are protective factors toward cognitive function decline. Higher educational level or literacy in certain individuals is also related to the decreased risk of cognitive function decline (Baumgart et al., 2015).

Brain trauma is related to the risk of cognitive function decline and dementia. Based on meta-analyses of cohort studies, depression history is related to the increased risk of cognitive function decline. Several cohorts and observational studies correlate sleeping disorders such as insomnia and sleep apnea with the risk factor of cognitive function decline (Baumgart et al., 2015).

\section{AUTHOR CONTRIBUTION}

Sandy Anandhita, Fatichati Budiningsih, and Arief Nurrudhin measured the sample's cognitive functions, measured calcidiol level, analyzed data, interpret data, and wrote the article.

\section{CONFLICT OF INTEREST}

There was no conflict of interest.

\section{FUNDING AND SPONSORSHIP}

There was no external funding

\section{ACKNOWLEDGEMENT}

We give our gratitude to the Internal Medicine Department, Dr. Moewardi Hospital, Surakarta, Central Jave for allowing us to conduct data collection. 


\section{REFERENCE}

Anjum I, Jaffery S, Fayyaz M, Samoo Z, Anjum $S$ (2018). The role of vitamin $D$ in brain health: A mini literature review. Cureus 10(7): e 2960. https://doi.org/$10.7759 \% 2$ Fcureus.2960.

Annweiler C (2016). Vitamin D in dementia prevention. New York Acad Sci. 1367(1): 57-63. https://doi.org/10.1111/nyaS. 13058

Baumgart M, Snyder HM, Carrilo MC, Fazio S, Kim H, Johns H (2015). Summary of the evidence on modifiable risk factors for cognitive decline and dementia: A population-based perspective. Alzheimers Dement. 11(6): 718-726. https://doi.org/10.1016/j.jalz.2015.05.016.

Cooper SA, McLean G, Guthrie B, McConnachie A, Mercer S, Sullivan F, Morrison $J$ (2015). Multiple physical and mental health comorbidity in adults with intellectual disabilities: Population-based cross-sectional analysis. BMC Fam Prac. 16: 110. https://doi.org/10.1186/s12875-015-0329-3

Holick MF, Binkley NC, Bischoff-Ferrari HA, Gordon CM, Hanley DA, Heaney RP, Murad MH et al. (2011). Evaluation, treatment, and prevention of vitamin $\mathrm{D}$ deficiency: An endocrine society clinical practice guideline. J Clin Endocrinol
Metab. 96(7): 1911-1930. https://doi.org/10.1210/jc.2011-0385.

Qizilbash N, Gregson J, Johnson ME (2015). BMI and risk of dementia in two million people over two decades: A retrospective cohort study. Lancet Diabetes Endocrinol. 3(6): 431-436. https://doi.org/10.1016/S2213-8587(15)00033-9.

Rouch L, Cestac P, Hanon O, Cool C, Helmer C, Bouhanick B, Chamontin B, et al. (2015). Antihypertensive drugs, prevention of cognitive decline and dementia: A systematic review of observational studies, randomized controlled trials and meta-analyses, with discussion of potential mechanisms. CNS Drugs. 29(2): 113-130. https://doi.org/10.1007/s40263-015-0230-6

Setiati S, Harimurti K, Dewiasty E, Istanti R (2011). Predictors and scoring system for health-related quality of life in an Indonesian community-dwelling elderly population. Acta Med Indones. 43(4): 237-42. https://www.ncbi.nlm.nih.gov/pubmed/22156355.

Sommer I, Griebler U, Kien C, Auer S, Klerings I (2017). Vitamin D deficiency as a risk factor for dementia: A systematic review and meta-analysis. BMC Geriatrics. 17(1):16. https://doi.org/10.1186/s12877-016-0405-0. 